\title{
Thermal behavior of friction clutch disc based on uniform pressure and uniform wear assumptions
}

\author{
Oday I. ABDULLAH ${ }^{1,2, *}$, Josef SCHLATTMANN ${ }^{1}$ \\ ${ }^{\prime}$ System Technologies and Mechanical Design Methodology, Hamburg University of Technology, Hamburg 21073, Germany \\ ${ }^{2}$ Department of Energy Engineering, College of Engineering, University of Baghdad, Baghdad-Aljadria 47024, Iraq \\ Received: 11 May 2016 / Revised: 22 June 2016/Accepted: 04 July 2016 \\ (C) The author(s) 2016. This article is published with open access at Springerlink.com
}

\begin{abstract}
High temperatures appear in the contacting surfaces of a single-disc clutch system (friction clutch disc, flywheel and pressure plate) due to the relative motion between these parts during the sliding period. These high temperatures are responsible for several disadvantages such as increasing wear rate, surface cracks and permanent distortions. In some cases, these disadvantages may lead the contacting surfaces to failure before the expected lifetime. In this work, mathematical models of the friction clutch system (single-disc clutch) were built to find the temperature field during the sliding period (single engagement). Analysis has been completed using developed axisymmetric models to simulate the friction clutch system during the engagement. The surface temperatures are found based on uniform pressure and uniform wear assumptions.
\end{abstract}

Keywords: dry friction clutch; thermal analysis; finite element analysis; uniform wear assumption; uniform pressure assumption

\section{Introduction}

The sliding systems such as automotive brakes and clutches consist of two or more bodies which press together and slide against each other. One of the contact bodies must be a conductor to dissipate the heat and have a good resistance to wear, while the other body should be an insulator and have a high value of coefficient of friction. The interaction between the heat generated appears between the contact surfaces due to the relative speed between them, and thermal deformation and the elastic contact will change the contact pressure distribution. This interaction in some cases will lead to change the status of the sliding system from stable zone to unstable zone. In order to keep the friction system in the stable zone, it should avoid thermal failure reasons such as excessive sliding speed, wrong selection of friction material, etc.

Newcomb [1] presented an analytical solution to

* Corresponding author: Oday I. ABDULLAH.

E-mail: odayia2006@yahoo.com obtain the surface temperature with time during the braking process assuming a uniform deceleration. He studied the effect of a non-uniform pressure distributed circumferentially along the lining. His approach showed largely agreement with the experimental results. After one year, Newcomb [2] investigated the torque capacity and the amount of heat dissipated of the dry clutch during a single engagement assuming a uniform wear of the clutch surfaces. He calculated the temperatures at various depths inside the contacting elements of the clutch and at any time during the slipping period. The research results showed that the maximum temperature of the frictional surface affected the pressure plate.

El-Sherbiny and Newcomb [3] used finite difference method to set up equations to express the heat balance at every region in the clutch system. He determines the temperatures at various elements when band contact occurs between the rubbing surfaces during the operation of an automotive clutch. Temperature distributions were determined of the contact area for different bands width on the two clutches facing. Both 
single and repeated engagements made at regular interval are considered.

Yevtushenko et al. [4] applied one-dimensional transient heat conduction to study the contact problem of a sliding of two semi-spaces, which induces the effects of friction and the heat generated during the braking. In their analysis, they assumed that the capacity of the frictional source on the contact plane depends on the time of braking. The problem is solved exactly using Laplace transform technique. The numerical results of the temperature are obtained for different values of input parameters, which characterize the duration of the increase of the contact pressure during braking from zero to the maximum value. An analytical formula for the abrasive wear of the contact plane is obtained assuming that the wear coefficient is a linear function with the contact temperature.

Grzes [5] performed a transient thermal analysis of disc brake in a single brake application to examine the effect of the angular speed and the contact pressure on the temperature field of disc brake. A parabolic heat conduction equation for the two-dimensional model was used to obtain the numerical simulation. The results showed that both rotating speed of the disc and the contact pressure with specific material properties greatly affect the temperature fields of the disc brake.

Ivanović et al. [6] presented a pragmatic semiphysical approach to model the thermal dynamic behavior of wet clutch. The thermal energy balance was considered the base to investigate the heat transfer mechanisms in the separator plate. The coefficient of friction and the thermal properties are considered the most important parameters which effect on the wet clutch dynamics response. Moreover, the effects of the coefficient of friction on the slipping speed of the clutch, the applied force, and the frictional surface temperatures have been studied. The results of the dynamic thermal model were experimentally validated.

Yevtushenko and Kuciej [7] investigated a transient thermal problem of three-elements (disc/pad/caliper) with time-dependent. The effects of Biot number and the duration of the pressure increasing from zero at the initial moment of time to nominal value at the moment of a stop on the values of the temperature of the cast iron disc/metal ceramic and pad/steel caliper have been studied. The research results showed that the effect of Biot number will reduce the heat transfer through the contact surface.

Abdullah and Schlattmann [8-15] study the thermoelastic behavior of a single and multi-disc friction clutches during the beginning of the engagement. They also investigated the effect of pressure between contact surfaces when it is varying with time on the temperature field and the internal energy of clutch disc using two approaches; heat partition ratio approach computes the heat generated of each part individually whereas the second approach applies the total heat generated of the whole model using the contact model. Furthermore, they studied the effect of engagement time, sliding speed function, thermal load, and dimensionless disc radius (inner disc radius/outer disc radius) on the thermal behavior of the friction clutch during the sliding period. They concluded that the restriction condition and material property modulus of elasticity are very effective on the contact pressure distribution and temperature field during the sliding period.

The objective of this work is to develop mathematical models of a single-disc clutch based on uniform pressure and uniform wear assumptions to find the temperature distribution during the sliding period. Furthermore, comparisons have been made between the results obtained when assuming a uniform pressure between the contact surfaces and those obtained assuming uniform wear. The results showed that each assumption has different temperature distribution during the sliding period.

\section{Energy dissipation based on frictional force}

Heat generated due to the sliding between two bodies will raise the temperatures of the contact surfaces as a result of friction phenomenon, as shown in Fig. 1. The first law of thermodynamic states that the change in the input energy to the sliding system $U_{\text {in }}$ is equal to the sum of the internal energy of the system $U_{\text {accumulated (accumulated or stored internally) and the }}$ energy output to the surrounding $U_{\text {out }}$ (dissipated externally) [16].

$$
U_{\text {in }}=U_{\text {out }}+U_{\text {accumulated }}
$$

The input energy in the friction case is the product of 


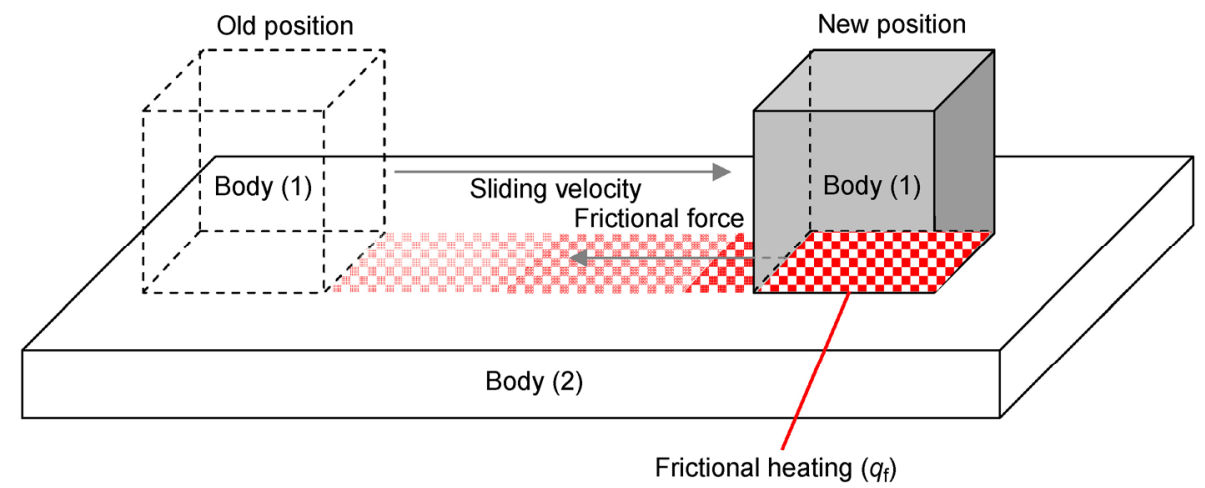

Fig. 1 Schematic view of frictional sliding between two bodies.

the frictional force $F_{\mathrm{f}}$ and the sliding speed $V_{\mathrm{s}}$. The rate of the input energy at the frictional interface is balanced by the heat conduction and the mechanical energy transmission moving away from the interface, either into the contact bodies or the surrounding. The partition of energy during the friction under various conditions is yet to be clearly determined. When the speed increases less and less friction energy perhaps as little as $5 \%$ consumed or stored in the material as microstructural defects such as dislocations, the energy produces phase transformations, surface energy of new wear particles and propagating subsurface cracks, etc. The rest of the energy is dissipated as a heat or melts the sliding interface. The energy that cannot be removed rapidly from the interface will cause raises in the values of the temperature locally. The temperatures which appear in the sliding process can be classified into two types [16]:

- The flash temperature (localized): The maximum friction-induced temperature of the tips of the interacting asperities. This temperature occurs when the sliding surfaces touch at only a few locations at any instant. The energy is concentrated there and the heating is particularly intense. The concept and calculation of the flash temperatures are explained with details in Ref. [17].

- The mean surface temperature (bulk): The average temperature over the nominal contact zone.

The rate of the heat generated based on the friction force during the slipping between two bodies (e.g., automotive brakes and clutches) is given as follows [18]:

$$
q_{\mathrm{f}}=\mu p V_{\mathrm{s}}, \quad 0 \leq t \leq t_{\mathrm{s}}
$$

where $\mu$,pand $V_{\mathrm{s}}$ are the coefficient of friction, contact pressure and sliding speed, respectively.
It can be obtained the rate of the heat generated during slipping period in the friction clutches under a uniform pressure condition between the contact surfaces using the following formula:

$$
q_{\mathrm{f}}(r, t)=\frac{3}{2 \pi} \frac{T_{\mathrm{r}} \omega_{\mathrm{r}} r}{n_{\mathrm{p}}\left(r_{\mathrm{o}}^{3}-r_{\mathrm{i}}^{3}\right)}, 0 \leq t \leq t_{\mathrm{s}}
$$

where $T_{\mathrm{r}}, \omega_{\mathrm{r}}, r, n_{\mathrm{p}}, r_{\mathrm{i}}$ and $r_{\mathrm{o}}$ are torque capacity of clutch, angular sliding speed, disc radius, number of friction surfaces in clutch system, inner disc radius and outer disc radius, respectively.

The heat generated during slipping period in the friction clutches under a uniform wear condition is

$$
q_{\mathrm{f}}(t)=\frac{1}{\pi} \frac{T_{\mathrm{r}} \omega_{\mathrm{r}}}{n_{\mathrm{p}}\left(r_{\mathrm{o}}^{2}-r_{\mathrm{i}}^{2}\right)}, 0 \leq t \leq t_{\mathrm{s}}
$$

Figure 2 shows the variation of the heat generated (heat flux) with disc radius during the sliding period for both cases (uniform pressure and uniform wear conditions).

\section{Mathematical model}

The starting point of the temperature field analysis of a clutch system is the parabolic heat conduction equation in the cylindrical coordinate system $(r$-radial coordinate $(\mathrm{m}), \theta$ - circumferential coordinate $\left({ }^{\circ}\right)$, and $z$-axial coordinate (m)) [19], as shown in Fig. 3.

$$
\begin{aligned}
& \frac{\partial^{2} T}{\partial r^{2}}+\frac{1}{r} \frac{\partial T}{\partial r}+\frac{1}{r^{2}} \frac{\partial^{2} T}{\partial \theta^{2}}+\frac{\partial^{2} T}{\partial z^{2}}=\frac{1}{k} \frac{\partial T}{\partial t}, \\
& r_{\mathrm{i}} \leq r \leq r_{\mathrm{o}}, 0 \leq \theta \leq 2 \pi, 0 \leq z \leq \delta, t>0
\end{aligned}
$$

where $k$ is the thermal diffusivity $(k=K /(\rho c)), r_{\mathrm{i}}$ is the 
(a) Uniform pressure

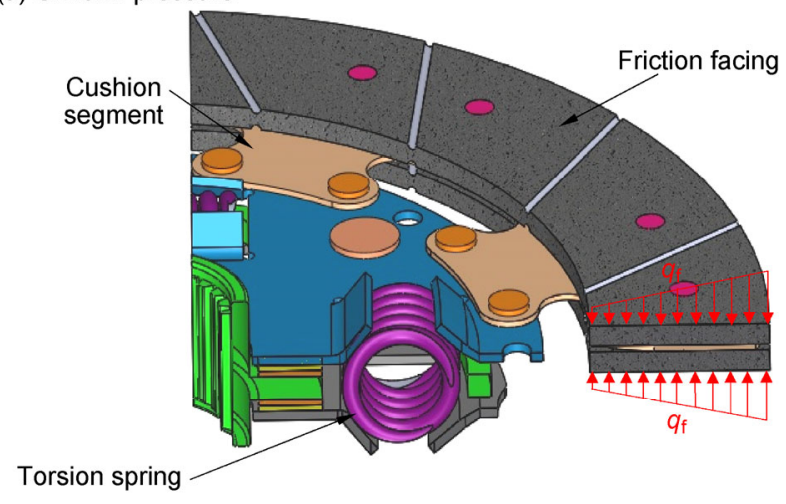

(b) Uniform wear

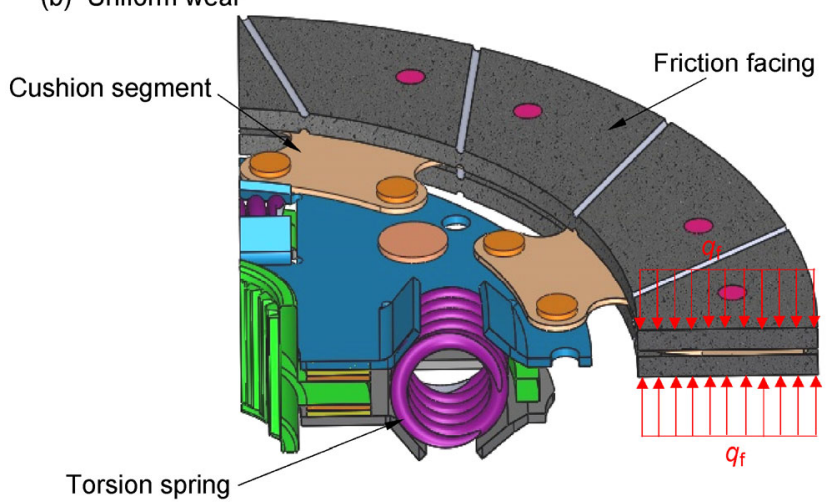

Fig. 2 Variation of heat flux on the surfaces of a clutch disc during the sliding period.

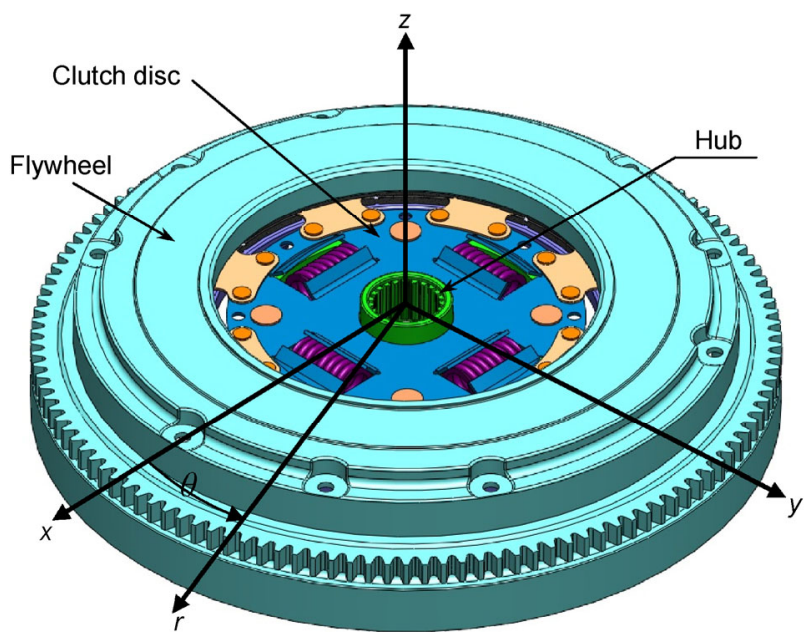

Fig. 3 Three-dimensional model of a single-disc clutch system.

inner disc radius, $r_{\mathrm{o}}$ is the outer disc radius of the clutch, and $\delta$ is the thickness of the contacting parts. Hence the distribution of heat flow will be uniform in circumferential direction, which means that the temperature and heat flow will not vary in $\theta$ direction, and thus the heat conduction equation reduces to (Fig. 4)

$$
\frac{\partial^{2} T}{\partial r^{2}}+\frac{1}{r} \frac{\partial T}{\partial r}+\frac{\partial^{2} T}{\partial z^{2}}=\frac{1}{k} \frac{\partial T}{\partial t}, r_{\mathrm{i}} \leq r \leq r_{\mathrm{o}}, 0 \leq z \leq \delta, t>0
$$

Owing to the symmetry in the geometry and the boundary conditions of the clutch disc in $z$-axis, it is possible to simulate only the half of the cutch disc to reduce the time consumption for calculation. The boundary and initial conditions of a clutch disc (upper half) without grooves are given as follows (Fig. 4):

$$
\begin{aligned}
& \left.K_{\mathrm{cu}} \frac{\partial T}{\partial r}\right|_{r=r_{0}}=h\left[T\left(r_{\mathrm{o}}, z, t\right)-T_{\mathrm{a}}\right], \\
& 0 \leq \theta \leq 2 \pi, 0 \leq z \leq t_{\mathrm{cu}} / 2, t \geq 0
\end{aligned}
$$

where $T_{\mathrm{a}}$ is the ambient surrounding temperature and $h$ is the convection heat transfer coefficient.

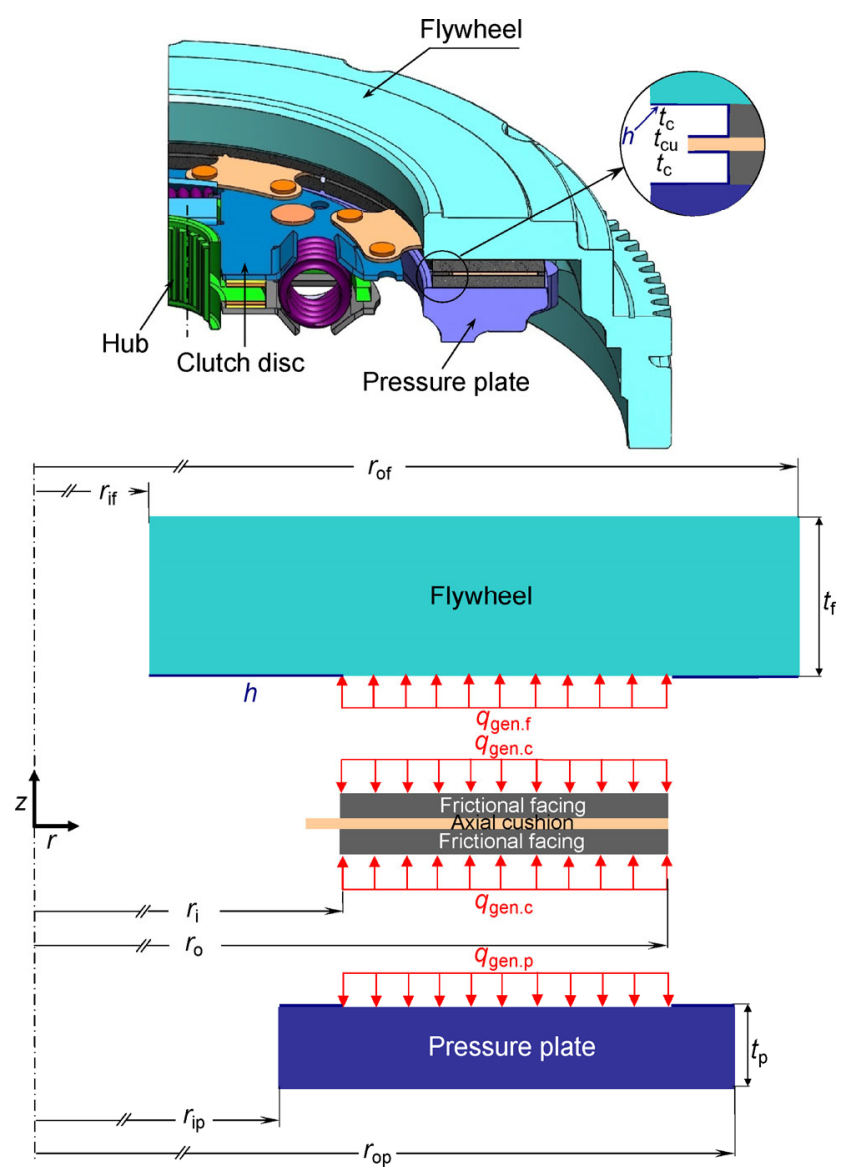

Fig. 4 Axisymmetric model of a clutch system with boundary conditions. 


$$
\begin{gathered}
\left.K_{\mathrm{c}} \frac{\partial T}{\partial r}\right|_{r=r_{0}}=h\left[T\left(r_{\mathrm{o}}, z, t\right)-T_{\mathrm{a}}\right], \\
0 \leq \theta \leq 2 \pi,\left(t_{\mathrm{cu}} / 2\right) \leq z \leq\left(t_{\mathrm{cu}} / 2\right)+t_{\mathrm{c}}, t \geq 0 \\
\left.K_{\mathrm{c}} \frac{\partial T}{\partial z}\right|_{z=\left(t_{\mathrm{cu}} / 2\right)+t_{\mathrm{c}}}=q_{\mathrm{c}}(r, t), \\
r_{\mathrm{i}} \leq r \leq r_{\mathrm{o}}, 0 \leq \theta \leq 2 \pi, 0 \leq t \leq t_{\mathrm{s}} \\
\left.K_{\mathrm{c}} \frac{\partial T}{\partial r}\right|_{r=r_{\mathrm{i}}}=h\left[T\left(r_{\mathrm{i}}, z, t\right)-T_{\mathrm{a}}\right], \\
0 \leq \theta \leq 2 \pi,\left(t_{\mathrm{cu}} / 2\right) \leq z \leq\left(t_{\mathrm{cu}} / 2\right)+t_{\mathrm{c}}, \quad t \geq 0
\end{gathered}
$$

The initial temperature is

$$
\begin{gathered}
T(r, \theta, z, 0)=T_{\mathrm{i}}, \\
r_{\mathrm{i}} \leq r \leq r_{\mathrm{o}}, 0 \leq \theta \leq 2 \pi, 0 \leq z \leq t_{\mathrm{c}}+\left(t_{\mathrm{cu}} / 2\right) \\
\left.\frac{\partial T}{\partial r}\right|_{r=r_{\mathrm{i}}}=0,0 \leq z \leq\left(t_{\mathrm{cu}} / 2\right), \quad t \geq 0 \\
\left.\frac{\partial T}{\partial z}\right|_{z=0}=0, \quad r_{\mathrm{i}} \leq r \leq r_{\mathrm{o}}, 0 \leq \theta \leq 2 \pi, \quad t \geq 0
\end{gathered}
$$

In this mathematical model, the angular sliding angular speed is assumed to decrease linearly with time as follows:

$$
\omega_{\mathrm{r}}(t)=\omega_{\mathrm{o}}\left(1-\frac{t}{t_{\mathrm{s}}}\right), \quad 0 \leq t \leq t_{\mathrm{s}}
$$

\section{Finite element formulation}

Axisymmetric model of two discs in contact $\Omega_{1}$ and $\Omega_{2}$ is shown in Fig. 5. One of these discs slides over the other one. The boundary and initial conditions of this model are described as follows:

$$
\begin{gathered}
T=T_{\mathrm{p}} \text { on } \Gamma_{\mathrm{T}} \\
q=-h\left(T-T_{\mathrm{a}}\right) \text { on } \Gamma_{\mathrm{h}} \\
q=q_{\mathrm{cu}} \text { on } \Gamma_{\mathrm{q}} \\
T=T_{\mathrm{i}} \text { at } t=0
\end{gathered}
$$

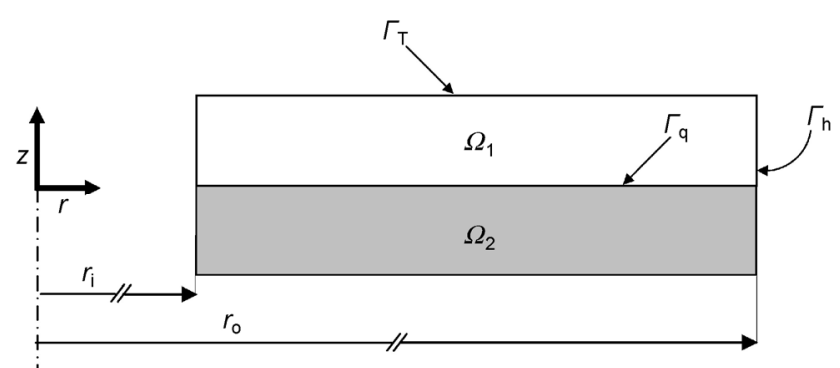

Fig. 5 Geometric model of the sliding system (two discs).
$T_{\mathrm{p}}$ is the prescribed temperature. $\Gamma_{\mathrm{T}}, \Gamma_{\mathrm{h}}$ and $\Gamma_{\mathrm{q}}$ are the boundaries on which temperature, convection and heat flux are prescribed of the system. The temperature was approximated over space as follows [20]:

$$
T(r, z, t)=\sum_{i=1}^{n} N_{i}(r, z) T_{i}(t)
$$

where $N_{i}$ is shape function, $n$ is the number of nodes in an element, and $T_{i}(t)$ is the time dependent nodal temperatures. The standard Galerkin's approach of Eq. (6) leads to the following equation [20]:

$$
\int_{\Omega} K N_{i}\left[\frac{\partial^{2} T}{\partial r^{2}}+\frac{1}{r} \frac{\partial T}{\partial r}+\frac{\partial^{2} T}{\partial z^{2}}-\rho C \frac{\partial T}{\partial t}\right] \mathrm{d} \Omega=0
$$

Using integration by parts of Eq. (20), it will obtain integral form of boundary conditions:

$$
\begin{gathered}
-\int_{\Omega} K\left[\frac{\partial N_{i}}{\partial r} \frac{\partial T}{\partial r}+\frac{\partial N_{i}}{\partial z} \frac{\partial T}{\partial z}-\frac{N_{i}}{r} \frac{\partial T}{\partial r}+N_{i} \rho C \frac{\partial T}{\partial t}\right] \mathrm{d} \Omega \\
+\int_{\Gamma} K N_{i} \frac{\partial T}{\partial r} l \mathrm{~d} \Gamma+\int_{\Gamma} K N_{i} \frac{\partial T}{\partial z} n \mathrm{~d} \Gamma=0 \\
\int_{\Gamma} K N_{i} \frac{\partial T}{\partial r} l d \Gamma+\int_{\Gamma} K N_{i} \frac{\partial T}{\partial z} n d \Gamma \\
=-\int_{\Gamma_{\mathrm{q}}} N_{i} q d \Gamma_{\mathrm{q}}-\int_{\Gamma_{\mathrm{h}}} N_{i} h\left(T-T_{a}\right) d \Gamma_{\mathrm{h}}
\end{gathered}
$$

Substituting Eq. (22) and spatial approximation Eq. (19) to Eq. (21), it can obtain the following equation:

$$
\begin{gathered}
-\int_{\Omega} K\left[\frac{\partial N_{i}}{\partial r} \frac{\partial N_{j}}{\partial r}+\frac{\partial N_{i}}{\partial z} \frac{\partial N_{j}}{\partial z}-\frac{N_{i}}{r} \frac{\partial N_{j}}{\partial r}\right] T_{j} \mathrm{~d} \Omega \\
-\int_{\Omega} \rho C N_{i} \frac{\partial N_{j}}{\partial t} T_{j} \mathrm{~d} \Omega-\int_{\Gamma_{\mathrm{q}}} N_{i} q \mathrm{~d} \Gamma_{\mathrm{q}} \\
-\int_{\Gamma_{\mathrm{h}}} N_{i} h\left(T-T_{a}\right) \mathrm{d} \Gamma_{\mathrm{h}}=0
\end{gathered}
$$

where $i$ and $j$ represent the nodes. Equation (23) can be written in matrix form as follows:

$$
C\left\{\frac{\partial T}{\partial t}\right\}+K\{T\}=\{R\}
$$

where $C$ is the heat capacity matrix, $K$ is the heat conductivity matrix, and $\{R\}$ is the thermal load. 
Also, it can be written this equation in different form as follows:

$$
C_{i j} \frac{\partial T_{j}}{\partial t}+K_{i j} T_{j}=R_{j}
$$

where

$$
\begin{aligned}
& C_{i j}=\int_{\Omega} \rho C N_{i} N_{j} \mathrm{~d} \Omega \\
& K_{i j}=\int_{\Omega} K\left(\begin{array}{l}
\frac{\partial N_{i}}{\partial r} \frac{\partial N_{j}}{\partial r}\left\{T_{j}\right\}+\frac{\partial N_{i}}{\partial z} \frac{\partial N_{j}}{\partial z}\left\{T_{j}\right\} \\
-\frac{N_{i}}{r} \frac{\partial N_{j}}{\partial r}\left\{T_{j}\right\}
\end{array}\right) \mathrm{d} \Omega \\
& +\int_{\Gamma} h N_{i} N_{j} \mathrm{~d} \Gamma \\
& R_{i}=-\int_{\Gamma_{\mathrm{q}}} q N_{i} \mathrm{~d} \Gamma_{\mathrm{q}}+\int_{\Gamma_{\mathrm{h}}} N_{i} h T_{\mathrm{a}} \mathrm{d} \Gamma_{\mathrm{h}}
\end{aligned}
$$

or in matrix form,

$$
\begin{gathered}
C=\int_{\Omega} \rho C \boldsymbol{N}^{\mathrm{T}} \boldsymbol{N} \mathrm{d} \Omega \\
\boldsymbol{K}=\int_{\Omega} K \boldsymbol{B}^{\mathrm{T}} \boldsymbol{D} \boldsymbol{B} \mathrm{d} \Omega+\int_{\Gamma} h \boldsymbol{N}^{\mathrm{T}} \boldsymbol{N} \mathrm{d} \Gamma
\end{gathered}
$$

Mesh quality has a significant effect on the errors existing in the numerical results and the time step was taken in the model validation phase to ensure that the most efficient combination of number of elements and number of nodes was employed, and the resulting mesh was suitable. It is essential to use a suitable mesh to obtain the results with high accuracy. Therefore, it is necessary to find the relationship between the largest element size in the direction of heat flow and the smallest time step size to improve the accuracy of the results. The minimum time step is [21]

$$
\Delta t=\frac{l_{\mathrm{e}}^{2}}{4 k}
$$

where $k$ is the thermal diffusivity, and $l_{e}$ is the value of the conducting length of an element (along the direction of heat flow) in the expecting highest temperature gradient. Figure 6 shows the axisymmetric finite element model of friction clutch system. The Crank-Nicolson method was selected as an unconditionally stable scheme in this analysis.

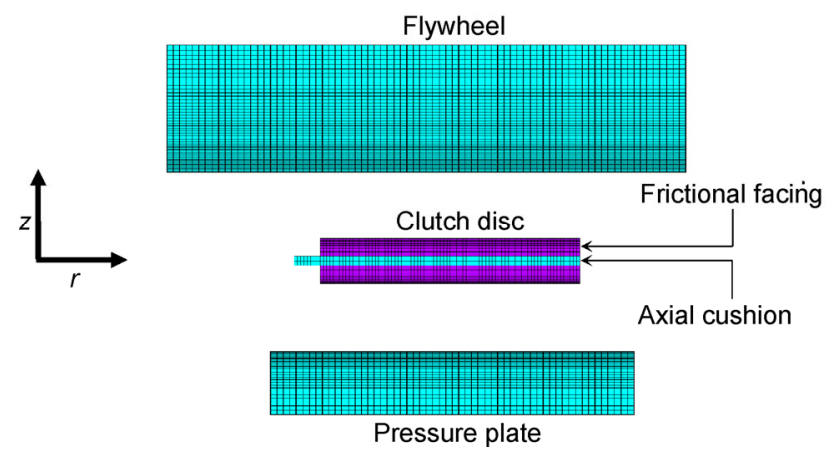

Fig. 6 Axisymmetric finite element model of a single-disc friction clutch system.

\section{Results and discussions}

The approach of present work was compared with the numerical results of $\mathrm{Fu}$ et al. [22] to find the maximum temperature $\left(T_{\max }\right)$ at inner and outer radius of friction clutch. Table 1 shows the comparison between the results obtained using our approach with other researcher which used different approach (Fu et al. [22]). In this table, the maximum difference not exceeds $1 \%$. The data for the verification case are shown in Table 2.

Figure 7 shows the developed axisymmetric finite element models of a clutch disc under uniform pressure

Table 1 The values of maximum temperature at inner and outer radius radii.

\begin{tabular}{ccc}
\hline & $T_{\max }$ at $r_{\mathrm{i}}(\mathrm{K})$ & $T_{\max }$ at $r_{\mathrm{o}}(\mathrm{K})$ \\
\hline Present work & 533.3 & 639.5 \\
Fu et al. [22] & 536.4 & 642.6 \\
Difference (\%) & 0.57 & 0.48 \\
\hline
\end{tabular}

Table 2 The parameters and material properties for verification case [22].

\begin{tabular}{ccc}
\hline Properties & Friction material properties & $\begin{array}{c}\text { Steel } \\
\text { properties }\end{array}$ \\
\hline $\begin{array}{c}\text { Dimensional } \\
\text { parameters }\end{array}$ & $\begin{array}{c}\text { Interior diameter, } D_{1}=252 \mathrm{~mm} ; \\
\text { external diameter, } D_{2}=386 \mathrm{~mm} ; \\
\text { thickness, } t_{2}=5 \mathrm{~mm}\end{array}$ & $\begin{array}{c}\text { Thickness } \\
t_{1}=10 \mathrm{~mm} \\
t_{3}=5 \mathrm{~mm}\end{array}$ \\
$\begin{array}{c}\text { Modulus of } \\
\text { elasticity }(\mathrm{MPa})\end{array}$ & 70 & $2 \times 10^{5}$ \\
$\begin{array}{c}\text { Thermal conducti- } \\
\text { vity }(\mathrm{W} /(\mathrm{m} \cdot \mathrm{K}))\end{array}$ & 0.25 & 48 \\
$\begin{array}{c}\text { Specific heat } \\
\text { capacity }(\mathrm{J} /(\mathrm{kg} \cdot \mathrm{K}))\end{array}$ & $1,337.6$ & 480 \\
Density $\left(\mathrm{kg} / \mathrm{m}^{3}\right)$ & 1,300 & 7,800 \\
\hline
\end{tabular}




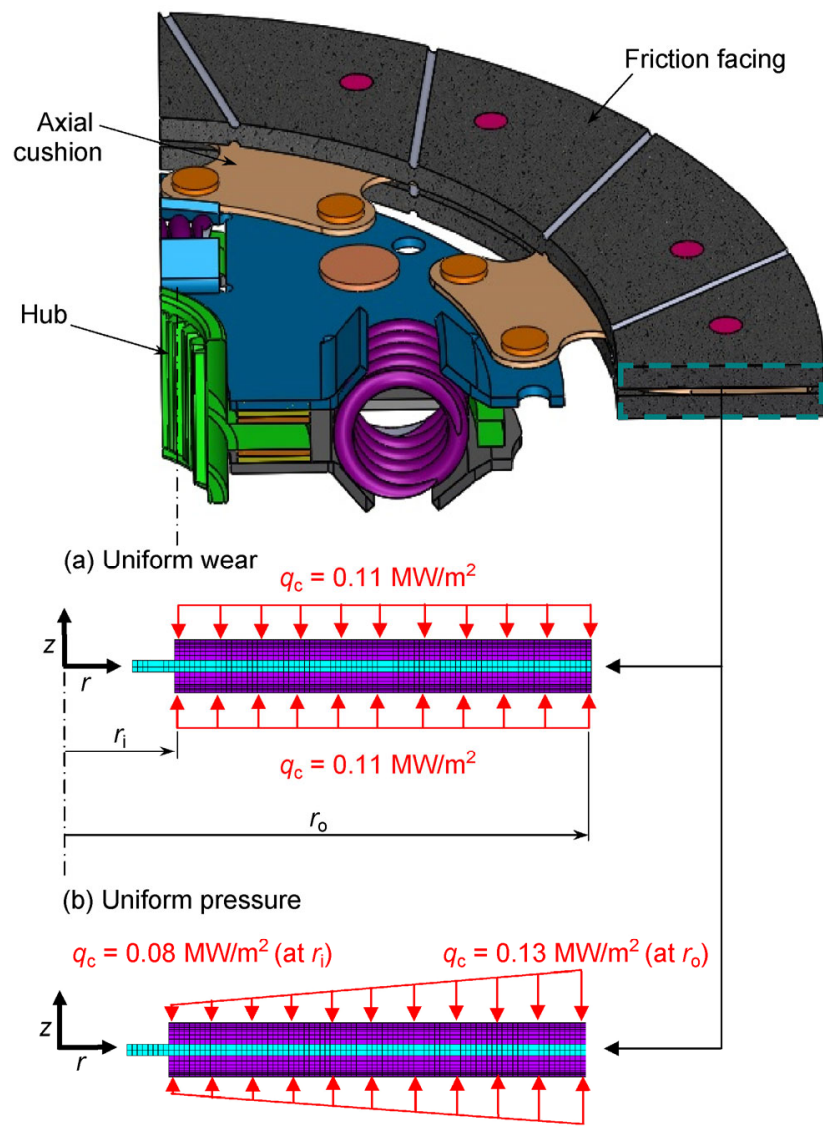

Fig. 7 Axisymmetric finite element models of clutch disc under different types of load, 8 nodes thermal element (PLANE77), number of elements $=1,776$.

and uniform wear assumptions. The slipping time is $0.4 \mathrm{~s}$ and the initial angular sliding speed $\omega_{\mathrm{o}}$ is assumed to be linearly decays and finally reaches zero at the end of the slipping period (Eq. (14)). The heat transfer coefficient was changed as a function of the relative surface speed $\left(V_{\mathrm{r}}\right)$ according to Czél et al. [23]: at a stationary position the value of heat transfer coefficient is $5 \mathrm{~W} /\left(\mathrm{m}^{2} \cdot \mathrm{K}\right)$. At $V_{\mathrm{r}}=14.8 \mathrm{~m} / \mathrm{s}$, the heat transfer coefficient is $40 \mathrm{~W} /\left(\mathrm{m}^{2} \cdot \mathrm{K}\right)$. In all computations, it has been assumed a homogeneous and isotropic material; all parameters and materials properties are listed in Table 3. All values and parameters referred to the axial cushion, friction material, flywheel and pressure plate in the following considerations will have bottom indexes $\mathrm{cu}, \mathrm{c}, \mathrm{f}$, and $\mathrm{p}$, respectively.

Figures $8(\mathrm{a})-8$ (h) show the variation of the surface temperature with disc radius of clutch disc assuming uniform wear and uniform pressure between the contact surfaces, respectively. It can be noticed that
Table 3 Model parameters and material properties.

\begin{tabular}{|c|c|}
\hline Parameters & Values \\
\hline Inner disc radius, $r_{\mathrm{i}}(\mathrm{m})$ & 0.085 \\
\hline Outer disc radius, $r_{\mathrm{o}}(\mathrm{m})$ & 0.135 \\
\hline Torque, $T(\mathrm{~N} \cdot \mathrm{m})$ & 580 \\
\hline Maximum pressure, $p_{\max }(\mathrm{MPa})$ & 0.25 \\
\hline Coefficient of friction, $\mu[1]$ & 0.3 \\
\hline Number of friction surfaces, $n_{\mathrm{p}}[1]$ & 2 \\
\hline Maximum angular slipping speed, $\omega_{\mathrm{o}}(\mathrm{rad} / \mathrm{s})$ & 220 \\
\hline Conductivity of friction material, $K_{\mathrm{c}}(\mathrm{W} /(\mathrm{m} \cdot \mathrm{K}))$ & 0.75 \\
\hline $\begin{array}{l}\text { Conductivity of pressure plate, flywheel and axial } \\
\text { cushion, } K_{\mathrm{p}}, K_{\mathrm{f}} \text { and } K_{\mathrm{cu}}(\mathrm{W} /(\mathrm{m} \cdot \mathrm{K}))\end{array}$ & 56 \\
\hline Density of friction material, $\rho_{\mathrm{c}}\left(\mathrm{kg} / \mathrm{m}^{3}\right)$ & 1,300 \\
\hline $\begin{array}{l}\text { Density of pressure plate, flywheel and axial cushion, } \\
\rho_{\mathrm{p}}, \rho_{\mathrm{f}} \text { and } \rho_{\mathrm{cu}}\left(\mathrm{kg} / \mathrm{m}^{3}\right)\end{array}$ & 7,200 \\
\hline Specific heat of friction material, $c_{\mathrm{c}}(\mathrm{J} /(\mathrm{kg} \cdot \mathrm{K}))$ & 1,400 \\
\hline $\begin{array}{l}\text { Specific heat of pressure plate, flywheel and axial } \\
\text { cushion, } c_{\mathrm{p}}, c_{\mathrm{f}} \text { and } c_{\mathrm{cu}}(\mathrm{J} /(\mathrm{kg} \cdot \mathrm{K}))\end{array}$ & 450 \\
\hline Thickness of friction material, $t_{\mathrm{c}}(\mathrm{m})$ & 0.002 \\
\hline Thickness of axial cushion, $t_{\mathrm{cu}}(\mathrm{m})$ & 0.001 \\
\hline
\end{tabular}

the temperature values are approximately uniform distributed with disc radius (very small effect of the heat convection on the values of temperatures near the inner and outer disc radii) at certain time assuming uniform wear between the contact surfaces. In case when assuming uniform pressure between the contact surfaces, the values of temperatures increase linearly with disc radius at any time during the sliding period.

Figure 9 illustrates the variation of the maximum surface temperature assuming uniform wear and uniform pressure between the contact surfaces, respectively. It can be seen for both assumptions that the temperature starts from an initial value $\left(T_{\mathrm{i}}\right)$ at beginning of slipping $(t=0)$ and increases to the maximum value $\left(T_{\max }\right)$ approximately at half time of slipping period $\left(t_{\mathrm{s}} \approx 0.2 \mathrm{~s}\right)$, and then it gradually decreases from $T_{\max }$ to the final temperature $\left(T_{\mathrm{f}}\right)$ at end of slipping period $\left(t_{\mathrm{s}}=0.4\right)$. Also, it can be observed that the maximum temperatures, which appeared on the surfaces of clutch disc assuming uniform pressure are greater than those obtained assuming uniform wear at any time during the sliding period. The difference between temperatures obtained from both assumptions increases with time at any certain time until approximately the mid time of a sliding period 

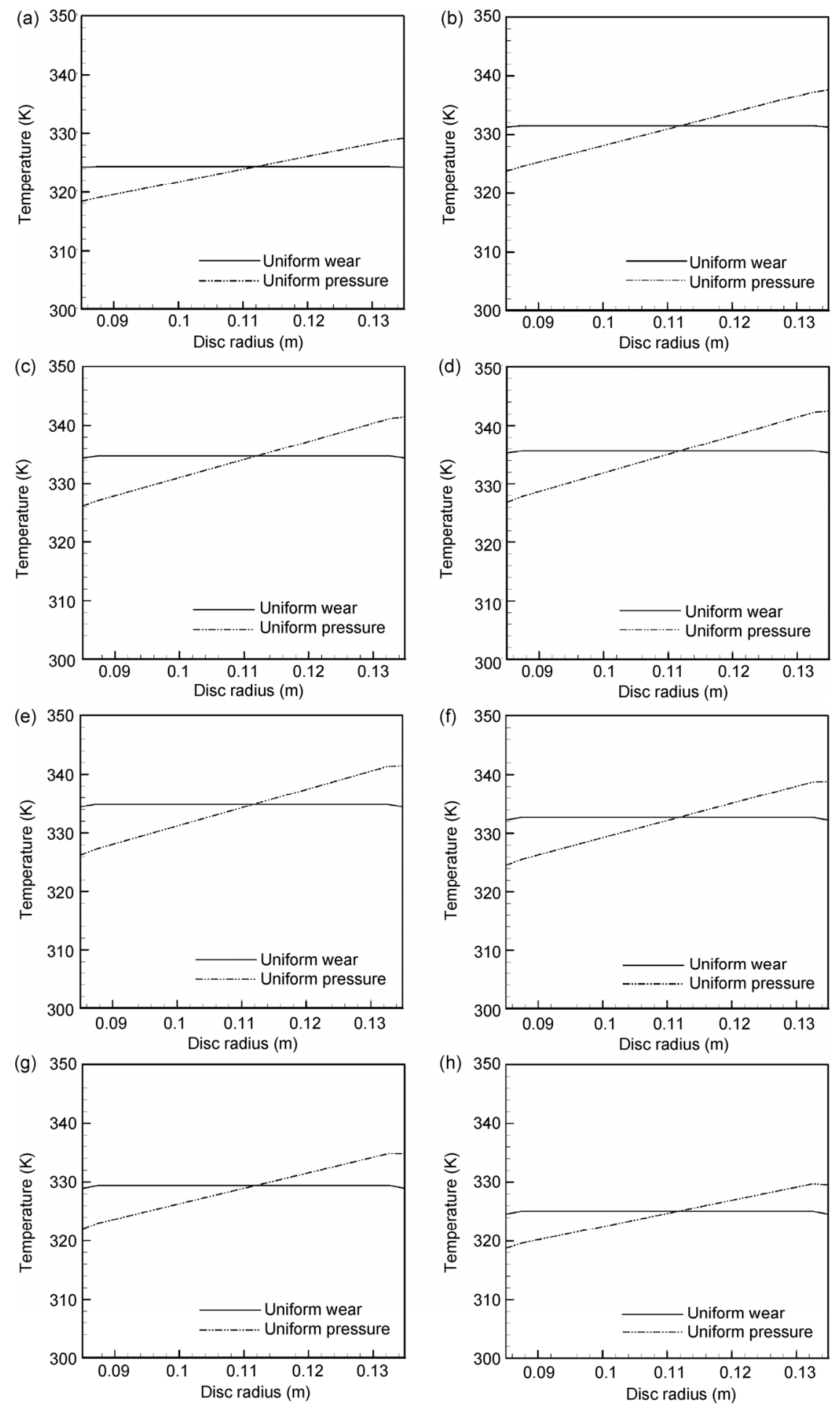

Fig. 8 Distribution of surface temperature with disc radius (a) at $t_{\mathrm{s}}=0.05$, (b) at $t_{\mathrm{s}}=0.1$, (c) at $t_{\mathrm{s}}=0.15$, (d) at $t_{\mathrm{s}}=0.2$, (e) at $t_{\mathrm{s}}=0.25$, (f) at $t_{\mathrm{s}}=0.3,(\mathrm{~g})$ at $t_{\mathrm{s}}=0.35$, and (h) at $t_{\mathrm{s}}=0.4$.

when the highest temperatures will appear, after this point the temperature difference will be decreased to the end of the sliding period.

The results are obtained assuming uniform wear between the contacting surfaces indicating that the values of temperature are approximately equal to the temperature at the mean disc radius assuming uniform pressure between the contact surfaces. However, the 


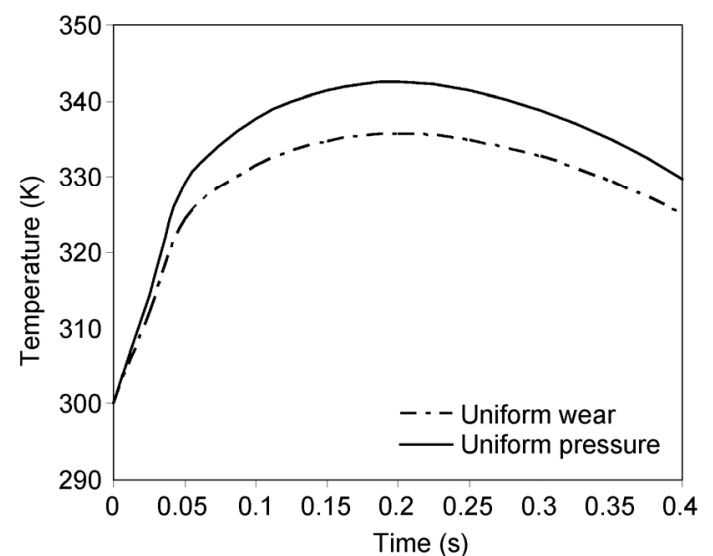

Fig. 9 Variation of the maximum surface temperature during the sliding period.

results obtained from second case (uniform pressure) show that the values of temperature are not uniform over the frictional facing, which increases linearly with disc radius. Thus, the maximum temperature will occur in the outer disc radius under the same boundary conditions. The results of temperature distribution assuming uniform pressure between the contact surfaces will lead the automotive designers to obtain more safe design of friction clutch, and subsequently get accurate estimates for the lifecycles of friction clutches.

\section{Conclusions and remarks}

In this work, axisymmetric models of a single-disc friction clutch based on different assumptions are developed. The results show the transient thermal behavior of a friction clutch system during the sliding period (heating phase), when the clutch system starts to engage. The analysis considers two types of load (heat flux) based on the design theories of the friction clutches. These theories are called uniform pressure and uniform wear. The results presented the temperature field of friction clutch disc based on uniform pressure and uniform wear assumptions.

This study highlights the error existing in the results and distribution of temperature field when assumes a uniform wear between the contact surfaces. The heat flux is uniformly distributed over the contact surfaces of clutch disc at any time when assumes a uniform wear. The results of temperatures based on this assumption approximately are equal to the temperature values at the mean disc radius when assumes a uniform pressure between the contact surfaces. The results under this consideration aren't giving the actual values of the maximum temperature and the temperature variation with disc radius.

On the other hand, when computes the temperature field of clutch disc based on a uniform pressure assumption, the heat flux increases linearly with disc radius. The minimum temperature value will occur at the inner disc radius and the maximum temperature value will occur at the outer disc radius at any time during the sliding period. A good agreement with results of other researchers using different approaches is obtained which proves the numerical model based on a uniform pressure assumption to deal with the sliding operation of friction clutches system.

The outcomes obtained from this work showed that the calculation of the temperature distribution based on a uniform wear will lead the automotive designers to obtain inaccurate estimation of lifecycles of friction clutches due to the error existing in this assumption.

Open Access: The articles published in this journal are distributed under the terms of the Creative Commons Attribution 4.0 International License (http:// creativecommons.org/licenses/by/4.0/), which permits unrestricted use, distribution, and reproduction in any medium, provided you give appropriate credit to the original author(s) and the source, provide a link to the Creative Commons license, and indicate if changes were made.

\section{References}

[1] Newcomb T P. Transient temperatures in brake drums and linings. Proc IMechE: Automobile Division 12(1): 227-244 (1958)

[2] Newcomb T P. Temperatures reached in friction clutch transmissions. J Mech Eng Sci 2(4): 273-287 (1960)

[3] El-sherbiny M, Newcomb T P. Temperature distributions in automotive dry clutches. Proc IMechE 190(1): 359-365 (1976)

[4] Yevtushenko A A, Ivanyk E G, Yevtushenko O O. Exact formulae for determination of the mean temperature and wear during braking. J Heat Mass Transfer 35(2): 163-169 (1999)

[5] Grzes P. Finite element analysis of disc temperature during braking process. J Acta Mechanica Et Automatica 3(4): 
36-42 (2009)

[6] Ivanović V, Herold Z, Deur J. Experimental characterization of wet clutch friction behaviors including thermal dynamics. SAE Int J Eng 2(1): 1211-1220 (2009)

[7] Yevtushenko A, Kuciej M. Temperature and thermal stresses in a pad/disc during braking. J Appl Therm Eng 30(4): 354359 (2010)

[8] Abdullah O I, Akhtar M J, Schlattmann J. Investigation of thermo-elastic behavior of multidisk clutches. $J$ Tribol 137(1): 1-9 (2015)

[9] Abdullah O I, Schlattmann J. An investigation into the thermal behavior of the grooved dry friction clutch. $J$ Tribol 136(3): 1-6 (2014)

[10] Abdullah O I, Schlattmann J. Computation of surface temperatures and energy dissipation in dry friction clutches for varying torque with time. Int J Automot Technol 15(5): 733-740 (2014)

[11] Abdullah O I, Schlattmann J, Al-Shabibi A M. Thermomechanical analysis of the dry clutches under different boundary conditions. Tribol Ind 36(2): 172-180 (2014)

[12] Abdullah O I, Schlattmann J. The effect of disc radius on heat flux and temperature distribution in friction clutches. J Adv Mater Res 505: 154-164 (2012)

[13] Abdullah O I, Schlattmann J. The correction factor for rate of energy generated in the friction clutches under uniform pressure condition. J Adv Theor Appl Mech 5(6): 277-290 (2012)

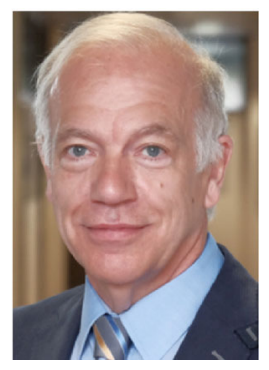

Josef SCHLATTMANN. He is a Univ.-Professor at the Hamburg University of Technology in the field of Systems Technology and Product Development Methodology. The fields of his research are systematically product development of

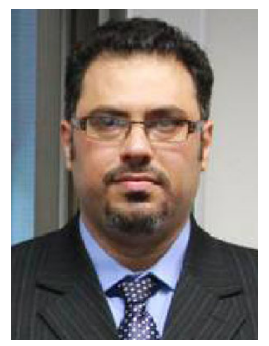

Oday Ibraheem ABDULLAH. He received his $\mathrm{Ph} . \mathrm{D}$. degree in mechanical engineering from Hamburg University of Technology in 2015. He is one of the faculty members in the Department of Energy Engineering/
[14] Abdullah O I, Schlattmann J. Finite element analysis of temperature field in automotive dry friction clutch. Tribol Ind 34(4): 206-216 (2012)

[15] Abdullah O I, Schlattmann J. Stresses and deformations analysis of a dry friction clutch system. Tribol Ind 35(2): 155-162 (2013)

[16] Blau P J. Friction Science and Technology from Concepts to Applications, $2^{\text {nd }}$ Edition. Boca Raton: CRC Press/Taylor and Francis, 2009.

[17] Bok H. The flash temperature concept. Wear 6(6): 483-494 (1963)

[18] Ling F F, Lai W M, Lucca D A. Fundamentals of Surface Mechanics, 2nd Edition. New York: Springer, 2002.

[19] Nowacki W. Thermoelasticity. Oxford (UK): Pergamon Press, 1962.

[20] Lewis R W, Nithiarasu P, Seetharamu K N. Fundamentals of the Finite Element Method for Heat and Fluid Flow. John Wiley and Sons, 2004.

[21] ANSYS. Contact Technology Guide. ANSYS, Inc, 13, 2010.

[22] Fu H, Fu L, Liu A, Zhang G-L. Finite element analysis of temperature field of clutch in tunnel boring machine. In Proceedings of the International Conference on Information Engineering_IEEE (WASE), Beidaihe, Hebei, China, 2010: 166-169.

[23] Czél B, Váradi K, Albers A, Mitariu M. Fe thermal analysis of a ceramic clutch. $J$ Tribol Int 42(5): 714-723 (2009)

machine elements and/or machine systems; tribology investigations; development of an autonomous biped robot, e.g., path planning, optimization of the control and the mechanical units; cooperation research work with the German industry.

College of Engineering/University of Baghdad since 2002. Now he is a research associate in System Technology and Mechanical Design Methodology Group/Hamburg University of Technology. His research areas cover the tribology, stress analysis, vibration analysis, and thermal analysis. 